\title{
Quantitative Study of the Effects of Long-Term Denervation on the Extensor Digitorum Longus Muscle of the Rat
}

\author{
CHRISTINE A. VIGUIE, DA-XING LU, SHI-KAI HUANG, HEMA RENGEN, \\ AND BRUCE M. CARLSON* \\ Department of Anatomy and Cell Biology and Institute of Gerontology, \\ University of Michigan, Ann Arbor, Michigan
}

\begin{abstract}
Background: In order to understand the cellular basis underlying the progressively poorer restorative capacity of long-term denervated muscle, we determined the effects of long-term denervation on the muscle fibers and satellite cell population of the rat extensor digitorum longus (EDL) muscle.

Methods: In 36 male rats, the right hind legs were denervated, and EDL muscles were removed 2, 4, 7, 12, and 18 months later. Muscles were either fixed for electron microscopic analysis or were dissociated into individual muscle fibers for direct fiber counting or for confocal microscopic analysis.

Results: The percentage of satellite cells rose from the $2.8 \%$ control value to $9.1 \%$ at 2 months of denervation; thereafter the percentage decreased to $1.1 \%$ at 18 months of denervation. The number of myonuclei per muscle fiber steadily declined from 410 in 4 month control muscle to 158 in 7 month denervated muscle. Up to 7 months of denervation, the total number of muscle fibers per muscle remained relatively constant at somewhat over 5,000. The calculated total satellite cell population in 4 month denervated EDL muscle was the same as that of controls at 65,000 , but by 7 months of denervation it had declined to 21,000. With increasing time of denervation, the number of cross-sectional profiles of muscle fibers not containing nuclei rose from $14 \%$ in control muscle to $49 \%$ in 12 month denervated muscle. This was correlated with a pronounced regular clumping of the nuclei, with pronounced nonnucleated segments between nuclear clumps.

Conclusions: Increasing times of denervation are accompanied by a pronounced decline in the number of myonuclei per muscle fiber and an initial rise and subsequent fall in satellite cell number. These changes are correlated with a decreasing restorative ability of these muscles over the same periods of denervation. Further work on the proliferative capacity of the remaining satellite cells is necessary before firm quantitative conclusions can be made. Anat. Rec. 248:346-354 1997. $\odot 1997$ Wiley-Liss, Inc.
\end{abstract}

Key words: skeletal muscle; rat; satellite cells; denervation

Skeletal muscle is an end organ of the peripheral nervous system, and its differentiation, structural maintenance, and function are directly regulated by its motor nervesupply. After denervation, a muscle rapidly loses mass and contractile function, and the muscle fibers undergo atrophy, with an accompanying series of changes in structure, biochemistry, and physiology (Gutmann, 1962; Sunderland and Ray, 1950; Miledi and Slater, 1969; Schmal bruch et al., 1991; Carlson et al., 1996).

Many questions remain concerning the problem of restoration of a denervated muscle. In clinical practice, after several months of denervation, ranging from 6-18 months, human skeletal muscles are typically not restored to full function even if regenerating nerve fibers grow into them (Harrison, 1989; Sunderland,
1978). Attempts to restore denervated rat muscles by grafting them into an innervated site have shown that muscles denervated for 2 months or less become restored as well as grafts of control muscles, but for muscles denervated between 2 and 7 months the degree of restoration of mass and contractile force after grafting declines sharply and remains at less than 31 and $13 \%$, respectively, of values for grafts of control muscles

Contract grant sponsor: National I nstitute of Health; contract grant number: P01 AG-10821.

*Correspondence to: Bruce M. Carlson, Department of Anatomy and Cell Biology, 4643 Medical Sciences II Building, University of Michigan, Medical School, Ann Arbor, MI 48109.

Received 7 May 1996; accepted 12 F ebruary 1997. 
for denervation periods exceeding 7 months (Carlson and Faulkner, 1988; Gulati, 1990; Carlson et al., 1996).

The poor restoration of long-term denervated muscle could be due to any of a number of factors, among which is a failure of regenerating nerves to reach the atrophic muscle fibers or the inability of the severely atrophic muscle fibers to respond to regenerating nerve fibers that reach them. The focus of this study is on the response of muscle fibers to long-term denervation. A specific question concerns the impact of long-term denervation on the satellite cell population within the extensor digitorum longus (EDL) muscle of the rat, because changes in the satellite cell population could be significant factors limiting the degree of restoration of a denervated muscle.

Satellite cells (Mauro, 1961) represent a source of new nuclear material for reversing the atrophy of denervated muscles, whether through the reversal of atrophy of intact denervated muscle fibers (Moss and Leblond, 1971; Ontell, 1975; Schiaffino et al., 1976) or through the regeneration of new muscle fibers (Snow, 1977; Carraro et al., 1985). Although it has frequently been reported that denervating a muscle causes an increase in the number of satellite cells (Lee, 1965; Hess and Rosner, 1970; Aloisi et al., 1973; Ontell, 1974), quantitative data have been presented mainly for muscles denervated for less than 2 months (Aloisi et al., 1973; Ontell, 1974; Hanzliková et al., 1975; McGeachie and Allbrook, 1978; Snow, 1983). Recently, Rodrigues and Schmalbruch (1995) reported on the effects of denervation at birth and at 5 weeks on satellite cell percentages in rat soleus and EDL muscles. There is very little information on satellite cells in long-term denervated muscles.

In this study a combination of techniques was used to estimate satellite cell populations of denervated rat EDL muscles. Through electron microscopic analysis it is possible to determine the relative proportions of satel lite cells and myonuclei, but absol ute numbers per muscle fiber cannot be readily determined. Confocal microscopic analysis of individual muscle fibers allows one to determine the total population of myonuclei plus satellite cell nuclei without differentiating between them. A combination of electron and confocal microscopic data all ows an estimate of the mean satel lite cell population per muscle fiber. Such data, combined with muscle fiber counts of EDL muscles after various periods of denervation, can be used to estimate thetotal satellite cell population within a denervated muscle. The object of this analysis was to determine if the reduction in restorative capacity of EDL muscles denervated between 2 and 7 months is accompanied by a corresponding reduction in the satellite cell population of the muscles.

\section{MATERIALS AND METHODS}

This study was conducted on 38 male rats of the $\mathrm{WI} / \mathrm{HicksCar}$ strain. At 4 months of age the right hind limbs were denervated by severing the sciatic nerve high in the thigh, ligating both proximal and distal nerve stumps, and reflecting the ends of both stumps into muscle tissue as far away from each other as possible. This procedure produces consistent denervation for periods as long as 22 months (Carlson and
Faulkner, 1988). All operations were carried out under ether anesthesia and were conducted in accordance with the guidelines of the American Physiological Society. EDL muscles were removed from denervated legs at $2,4,7,12$, and 18 months after denervation. Therats were then euthanized with an overdose of anesthetic.

\section{Satellite Cell Analysis}

For the analysis of satellite cell frequency, three EDL muscles from normal 6-month-old rats and muscles from 2, 4, 7, 12 (three muscles per time point), and 18 (two muscles) month denervated limbs were removed. The 6 month normal EDL muscles were chosen for electron microscopic controls because that age represents a stable adult level baseline for satellite cell counts. Very little change in the percentage of satellite cells in the EDL muscle occurs between 6 and 12 months. The muscl es were pinned at resting length on a wax plate and fixed by immersion in a solution containing 2.5\% glutaral dehyde in $0.1 \mathrm{M}$ phosphate buffer at $\mathrm{pH}$ 7.4. One hour later, muscles were cut into small blocks, fixed an additional $4 \mathrm{~h}$ or overnight in fresh fixative, and then postfixed for $1 \mathrm{~h}$ in $1 \%$ osmium tetroxide. Thetissues were then dehydrated in a graded series of ethanol and embedded in Spurr resin for electron microscopy. Transverse semithin sections were cut from each sample and processed for light microscopy for survey purposes. Thin sections were examined with a Philips CM-10 electron microscope.

For quantitative analysis, approximately 1,000 basement membrane profiles of muscle fibers from each experimental and control muscle were examined by electron microscopy, and the numbers of myonuclei and satellite cells were recorded. From the same crosssections, the numbers of muscle fiber cross-sections that did not contain any nuclei were tabulated. The frequency of satel lite cel Is was expressed as the percentage of the total number of nuclei observed beneath the basement membrane. ANOVA was used to analyze the quantitative data. A probability of $\mathrm{P}<0.05$ was se lected to determine significant differences between groups.

\section{Confocal Microscopic Analysis of Dissociated Muscle Fibers}

At $0,2,4$, and 7 months after denervation, EDL muscles were excised. For confocal microscopic analysis, normal 4-month-old EDL muscles (0 month denervation) were used as controls and as the basis for comparing nuclear counts and cytoplasmic volumes of denervated muscle fibers. After removal from the denervated legs, the muscles were fixed in $4 \%$ paraformaldehyde ( $\mathrm{pH}$ 7.4) for $2 \mathrm{~h}$, rinsed in phosphate buffered saline (PBS), and placed in $70 \%$ ethanol. Individual single muscle fibers were obtained manually by microdissection in a 1:1 solution of glycerol and $70 \%$ ethanol under a dissection microscope. Care was taken to obtain single complete muscle fibers from the core of the muscles. Single fibers were returned to PBS and exposed to propidium iodide ( $3 \mu \mathrm{M})$ for 5-7 min to label the nuclei. Once labeled, single fibers were rinsed in PBS and mounted in the presence of antifading reagents (Slow-Fade; Molecular Probes, Eugene, OR) with special precautions taken to preserve the threedimensional (3-D) structure of theisolated single muscle fibers. 
Muscle fibers were imaged on a BioRad (Hercules, CA) MRC-600 laser scanning confocal microscope, coupled to an inverted Nikon (Melville, NY) Diaphot light microscope with a $\times 40,0.85$ NA objective. The confocal microscope collects individual two-dimensional (2-D) X-Y 8 bit images at preset spatial locations along the Zaxis, providing a 3-D data set of a given area of the muscle fiber. The gain, dark current, and gamma settings were adjusted to obtain the widest possible contrast in the images. Myonuclei in general had a gray value of 250, muscle cytoplasm had a gray value of approximately 40, and the background had a value of $<5$ but $>1$. Three-dimensional data sets were transferred to a Sparc II UNIX workstation (SUN Microsystems, Mountain View, CA) for image processing and quantification.

Quantification of the absolute number of nuclei (myonuclei + satellite cells) along the muscle fiber was done by sequentially stacking theindividual 2-D images of a 3-D data set, with only the brightest components of an image contributing to the final image. This formed a filtered 2-D projection image. Following segmentation, only the labeled nuclei were present in the 2-D image. The segmented image was then counted automatically by using an interactive software package (ISee; I nnovation Corp., Research Triangle Park, NC). Muscle fibers were screened prior toimaging to ensure that only those without evidence of adhering connectivetissuewereimaged. Connective tissue contained fibroblasts which were readily stained by propidium iodide and would have erroneously altered the counts of nuclear numbers.

For quantification of cytoplasmic volume, each 2-D $768 \times 512$ pixel image was processed individually. I mages were thresholded to bring forth the muscle cytoplasm with the edges smoothed and detected by image processing. The output data file contained the number of pixels included within the thresholded region of each X-Y image. The 2-D areas of a 3-D data set were summed and multiplied by the Z axis increment to determine the volume of the 3-D data set.

Means and standard error of the mean were determined. Further analysis of one-way analysis of variance (ANOVA) was performed with a post hoc test set at a significance level of $\mathrm{P}<0.05$. Statistics were determined with the Systat Analysis program, version 2.0, for Madintosh.

\section{Muscle Fiber Counting}

In order to estimate the total satellite cell populations of denervated muscles, we made total muscle fiber counts on control, 4, and 7 month denervated EDL muscles. Because of geometrical artifacts inherent in making counts of muscle fiber cross-sections in normal EDL muscles (Maxwell et al., 1974), muscle fiber counts on control EDL muscles in 4-month-old rats were made by direct counting of muscle fibers dissociated by immersion in $15 \%$ nitric acid (Blaivas and Carlson, 1991). In muscles denervated for over a month, the angle of pennation of muscle fibers in relation to the long axis of the muscle is minimal, al lowing more accurate comparisons of counts of muscle fibers through sections taken at the midpoint of the muscle. Counting muscle fibers of denervated muscles by dissociation and direct counting under a dissecting microscope is not possible because of the extreme atrophy of some of the muscle fibers (Schmal bruch et al., 1991; Lu et al., 1997).
RESULTS

Denervated Muscle

A detailed morphological description of denervation atrophy from 2-18 months is given in the companion paper (Lu et al., 1997). Denervated EDL muscles underwent rapid atrophy (Fig. 1). At 2 months after denervation, differential muscle fiber atrophy was evident, with type 1 muscle fibers undergoing a much slower course of atrophy than type 2 muscle fibers ( $\mathrm{Lu}$ et al., 1997). In subsequent periods studied, all muscle fibers were severely atrophic, and with increasing denervation times muscle fibers became surrounded with layers of densely packed collagen fibers. The density of capillaries associated with muscle fibers also decreased considerably. Further progressive change in morphol ogy lessened after 12 months of denervation.

\section{Confocal Microscopic Study of Nuclear Number} and Cytoplasmic Volume on Isolated Muscle Fibers

The number of nuclei (myonuclei + satellite cells) within the basal lamina of the muscle fiber steadily declined as a function of the time of denervation (Table 1). Mean nucl ear numbers per millimeter of fiber length in 4 month control muscles were $34.2 \pm 5$. On a whole muscle fiber basis, fibers of the normal EDL muscle of 4-month-old control rats contained approximately 410 nuclei. This number declined by $36 \%$ at 2 months and by $68 \%$ at 7 months of denervation.

Nuclear length, as measured along the longitudinal axis of the muscle fiber, changed slightly but not significantly over the period of denervation. Mean length of nuclei in control muscle fibers was $17.0 \pm 0.7$ $\mu \mathrm{m}$. At 2,4 , and 7 months of denervation, the values were $15.4 \pm 0.9,16.7 \pm 0.4$, and $17.6 \pm 0.5 \mu \mathrm{m}$, respectively.

At increasing times of denervation, there was an increased incidence of regions of muscle fibers (up to 0.4 $\mathrm{mm}$ long) that contained no nucl ei at all. After 4 months of denervation, approximately one-fourth of the muscle fibers examined exhibited this morphological feature. Cross-striations could still be discerned in expanses of cytoplasm that contained no nuclei. By 7 months of denervation, most muscle fibers showed regularly spaced clusters of nuclei alternating with longer nucleus-free regi ons of cytoplasm (Fig. 2; see Table 2). With increasing time of denervation, increasingly large numbers of myonuclei departed from their normally parallel alignment to the long axis of the muscle fiber.

As compared with 4 month normal controls, mean cytoplasmic volume/millimeter of muscle fiber declined dramatically over the denervation period (Fig. 3). In normal 4-month-old WI/HicksCar EDL muscle fibers, the cytoplasmic volume per muscle fiber was $2.6 \pm$ $0.4 \times 10^{7} \mu \mathrm{m}^{3}$. Two months following denervation, the cytoplasmic volume had declined to $12 \%$ of control values. Cytoplasmic vol ume continued to decline to $4 \%$ and $2 \%$ of control values by 4 and 7 months, respectively, following denervation. The cytoplasmic volume/ nucleus ratio fell sharply from a control value of $7.0 \pm$ $0.5 \times 10^{4} \mu \mathrm{m}^{3}$ per nucleus (Fig. 4). At 2 months of denervation this ratio was $2.2 \%$ of control values, and the ratio dedined to $1.5 \%$ and $1.0 \%$ by 4 and 7 months, respectively, of denervation. 

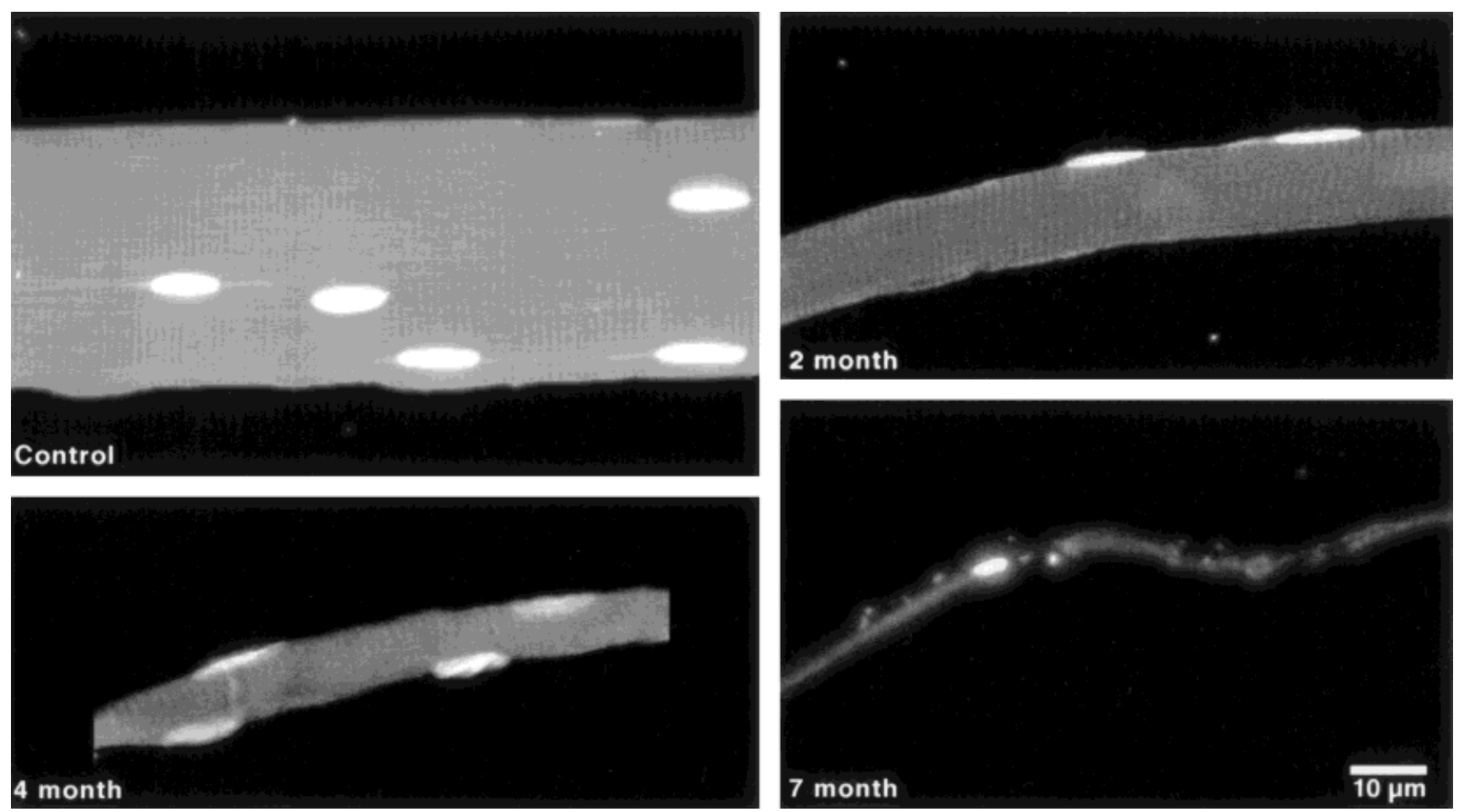

Fig. 1. Confocal microscopic images of segments of rat EDL muscle fibers at 0 (Control), 2, 4, and 7 months after denervation. All images were taken at the same magnification.

TABLE 1. Denervation effects on satellite cell populations in rat EDL muscles

\begin{tabular}{|c|c|c|c|c|c|c|c|}
\hline Denervation time & $\begin{array}{c}\text { Total } \\
\text { nudei/mm }\end{array}$ & $\begin{array}{l}\text { Total nudei/ } \\
\text { musde fiber }\end{array}$ & $\begin{array}{l}\text { Satellite } \\
\text { cell \% }\end{array}$ & $\begin{array}{l}\text { Satellitecells/ } \\
\text { musdefiber }\end{array}$ & $\begin{array}{l}\text { Total number } \\
\text { of musde fibers }\end{array}$ & $\begin{array}{l}\text { Total number } \\
\text { of satellitecells }\end{array}$ & $\begin{array}{l}\text { Total number } \\
\text { of myonuclei }\end{array}$ \\
\hline Control (4-month-old rats) & $34 \pm 5$ & 410 & $2.8 \pm 0.4^{1}$ & 11.5 & $5,709 \pm 212$ & 65,654 & $2,272,182$ \\
\hline 2 months & $22 \pm 2$ & 297 & 0.1 & 27 & - & - & - \\
\hline 4 months & $16 \pm 2$ & 208 & $6.5 \pm 1.0$ & 13.5 & $4,829 \pm 83$ & 65,192 & 946,484 \\
\hline $7 \mathrm{~m}$ & $11 \pm 2$ & 158 & 0.9 & 4.0 & $5,282 \pm 165$ & 21,128 & 813,428 \\
\hline 12 months & - & - & $1.2 \pm 0.2$ & - & - & - & - \\
\hline 18 months & - & - & $1.1 \pm 0.01$ & - & - & - & - \\
\hline
\end{tabular}

${ }^{1}$ Control musdes for satellitecell counts taken from 6-month-old rats.

\section{Counts of Satellite Cells}

In 2-month denervated muscles (taken from 6-monthold rats), the percentage of satellite cell profiles increased from control values (based on normal 6-monthold muscles) of $2.8 \%$ to $9.1 \%$ of the total nuclei beneath the basal lamina of the muscle fiber. This was followed by a steady decline to $1.1 \%$ of the total nuclei by 18 months of denervation (Table 1). On the same material, the percentage of muscle fiber cross-sections that contained no nuclei underwent a steady increase from a control value of $14.3 \%$ to $48.6 \%$ at 12 months of denervation (Table 2). Yet, among the fiber crosssections that did contain nuclei, multiple satellite cell nuclei or cytoplasmic profiles were frequently found even after prolonged denervation.

In normal and in short-term denervated muscle, satellite cells were situated close to their associated muscle fibers, typically being separated from them by a space of only 200A (Fig. 5). During the first 4 months of denervation, when the percentage of satellite cells was greatly increased over normal, it was not uncommon to encounter two or more satellite cells per cross-sectioned muscle fiber (Fig. 6). As many as four satellite cell nuclei and cytoplasmic processes of satellite cells have been found associated with a single cross-sectioned muscle fiber. Satellite cells with increased cytoplasmic volume and long cytoplasmic processes were commonly encountered, and in some regions irregular gaps appeared between the satellite cell and the muscle fiber (Fig. 6). In very long-term denervated muscle, satell itecells in various stages of activation werefound within a common basal lamina in association with small muscle fibers that appeared to be degenerating and/or regenerating.

\section{Muscle Fiber Counts}

Direct counts of dissociated muscle fibers in three pairs of normal EDL muscles from 4-month-old rats yielded a mean of 5,709 \pm 212 muscle fibers. Counts of muscle fibers from photographic montages of crosssections through the midpoint of three 4 month and 


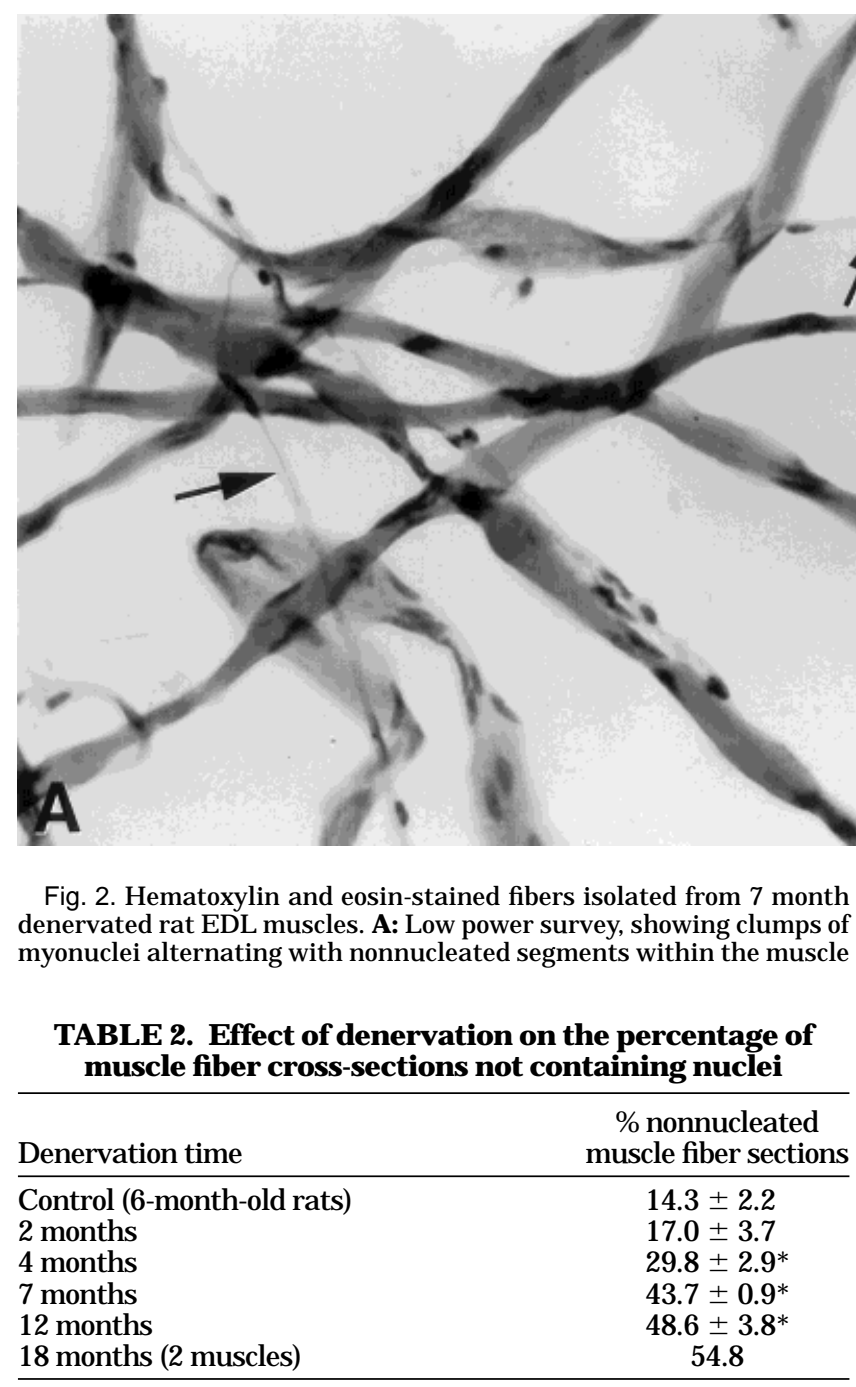

$* \mathrm{P}<0.05$ as compared with control group.

three 7 month denervated muscles yiel ded mean values of 4,829 \pm 83 and 5,282 \pm 165 muscle fibers, respectively (Table 1).

\section{DISCUSSION}

This study has shown that during the first 2 months following denervation there is a threefold increase in satel lite cells (expressed as a percentage of satel lite cell nuclei/satellite cell + myonuclei) over control levels. The early increase is foll owed by a steady decrease over subsequent months. A similar pattern was noted by Rodrigues and Schmalbruch (1995), but the difference between control and 2 month denervated levels in their experiment was considerably less than that recorded here. Rodrigues and Schmalbruch performed their denervations on 5 week rats, which are still in a rapid growth phase and have a higher percentage of satellite cells (nearly 6\%) than is found in rats between 4 and 12 months, where the percentage of satellite cells stabilizes to slightly below 3\% (this study; Gibson and Schultz, 1983). fibers. Two extremely thin muscle fibers (arrows) may represent newly regenerating muscle fibers. B,C: Higher power views of segments of muscle fibers, showing in greater detail the nuclear clumping.

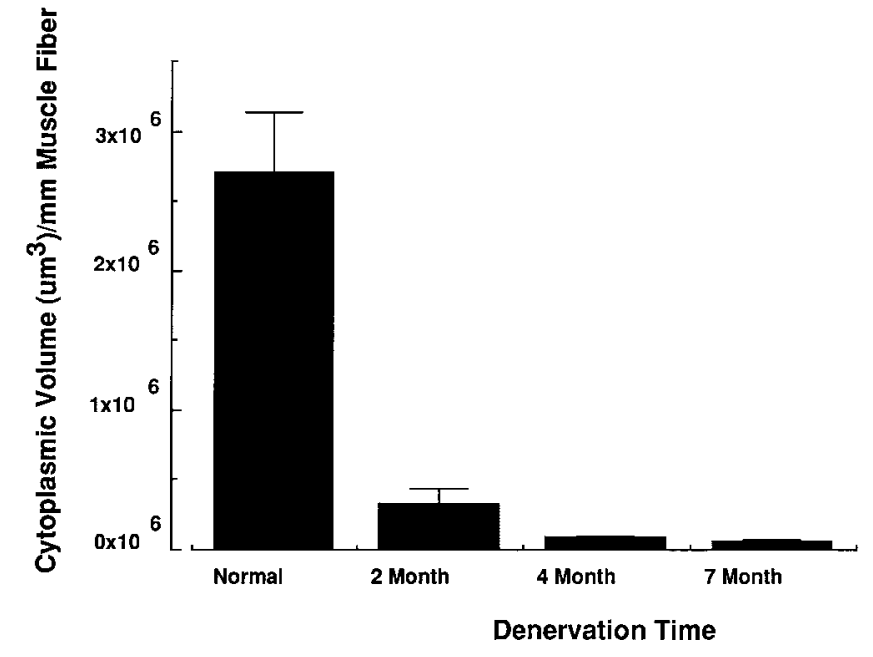

Fig. 3. Changes in cytoplasmic volume per millimeter of muscle fiber in rat EDL musclefibers over a 7 month period of denervation.

Satellite cell percentages alone do not reflect total satellite cell numbers in denervated muscle. When combined with total nuclear counts, however, they provide estimates of satellite cell populations associated with single muscle fibers (Table 1). Such estimates show a greater than twofold increase in satellite cell number per muscle fiber during the first 2 months following denervation. Because of the pronounced decline in overall nuclear numbers per muscle fiber after denervation, the total number of satel lite cells per fiber at 4 months postdenervation is only slightly above the preoperative level despite the fact that the percentage 


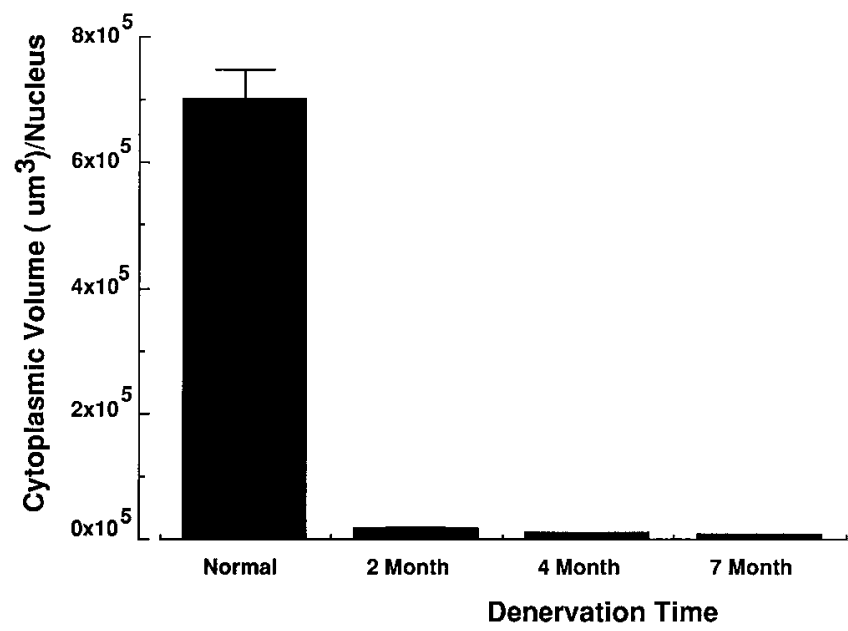

Fig. 4. Changes in cytoplasmic volume per nucleus in rat EDL muscle fibers over a 7 month period of denervation.

of satellite cells is still greater than twice control values. Only at 7 months after denervation, when the percentage of satellite cells has fallen to control values, does one find a threefold decrease in satellite cells per muscle fiber because of the dramatic decrease in the total number of nuclei per muscle fiber.

When the satellite cells/muscle fiber data are combined with total muscle fiber/muscle data, one can estimate the total satellite cell population in the EDL muscle at various periods of denervation (Table 1 ). The estimate of satellite cells in control EDL muscle derived by this methodology is roughly three times less than that published by Gibson and Schultz (1983), who used total DNA values as part of the basis for their estimates. This difference could be due to a number of factors, ranging from the strain of rat to the methodology used. Work in this laboratory (Viguie, unpublished) has shown $40 \%$ more nuclei per muscle fiber in Wistar than in Fischer-344 rats. Such data are not available for Sprague-Dawley rats, which were used by Gibson and Schultz. Cardasis and Cooper (1975) counted myonuclei and calculated satellite cell numbers in muscle fibers of the mouse gastrocnemius. In 63-day-old mice they found a mean of 355 myonuclei per fiber, and on the basis of a $6 \%$ incidence of satellite cells they cal culated a total of 21 satel lite cells per muscle fiber.

Although total muscle fiber counts were not done for 2 month denervated muscles, the stability of muscle fiber numbers through 7 months of denervation suggest that at 2 months of denervation the overall population of satellite cells in the EDL muscle considerably exceeds that of control muscle. The estimate of total satellite cells per EDL muscle at 7 months of denervation is only one-third of control values. Unfortunately, because of the extremely small size of many of the musclefibers in muscles denervated from 12-18 months, it was not possible either to isolate individual muscle fibers for confocal microscopy or to make accurate counts of total muscle fibers, but, on the basis of mass and morphology of these muscles (Carlson et al., 1996; Lu et al., 1997) combi ned with the percentages reported in this paper, it is realistic to assume that the total satellite cell population per muscle fiber is reduced even further with increasing time of denervation.

A number of reports have documented an increase in the percentage of satellite cells after denervation (Aloisi et al., 1973; Hanzliková et al ., 1975; McGeachie and Allbrook, 1978; Ontell, 1974; Rodrigues and Schmalbruch, 1995; Snow, 1983), but the basis for the increase in satellite cell number during the first 2 months after denervation remains to be defined. Some of the earlier reports (Lee, 1965; Hess and Rosner, 1970; Ontell, 1974) suggested that the increase in satellite cell number may be due to the separation of myonuclei from the denervated muscle fibers. Another interpretation, which is more in keeping with contemporary knowledge, is that the proliferation of existing satellite cells could account for the increase. Autoradiographic studies by McGeachie and Allbrook (1978) and Murray and Robbins (1982) have shown increases in the incorporation of $\mathrm{H}^{3}$-thymidine into nuclei associated with muscle fibers, but these studies were limited to the first week after denervation.

An important practical issue is whether or not the quantitative data on satellite cell numbers shed any light upon the results of attempts to restore long-term denervated muscle. Both Gulati (1990) and Carlson et al. (1996) found that grafts of 2 or 3 month denervated rat EDL muscles were restored to the same mass and contractile force as grafts of normal EDL muscles, but for longer periods of denervation restoration was less successful. The maximum tetanic force developed by grafts of 4 and 7 month denervated muscles declined in a straight line fashion from 2 month levels so that the recovery of force at 7 months was only $17 \%$ of that attained at 2 months. Beyond 7 months of denervation there was a continued slight decline in force. Grafts of normal muscle are restored through a combination of regeneration and reinnervation, and both could play a significant role in the success of restoration of grafts of previously denervated muscles.

The estimates of total satellite cell populations per muscle (Table 1) show no change from control in 4 month denervated muscles but a threefold decrease by 7 months of denervation. When these data are combined with estimates of the total number of myonuclei per muscle (Table 1), one can calculate that, in order to restore the control number of myonuclei, each satellite cell in a 7 month denervated muscle would have to produce approximately 70 progeny (six to seven doublings). However, without data on the number of progeny that could be produced per satellite cell in denervated muscle, it is difficult to determine if absolute numbers of satel lite cells represent a biol ogical limiting factor. Recent work from Partridge's laboratory (Rosenblatt et al., 1995) has shown that the satellite cells from a single EDL muscle fiber in the mouse can produce over 100,000 progeny in vitro. If such numbers are representative of the proliferative capacity of satellite cells in the rat, individual satellite cells would have to undergo an enormous reduction in their proliferative capacity for pure numbers of satellite cells in denervated muscl es to be a limiting factor. On the other hand, unfavorable environmental conditions in vivo could potentially severely limit the ability of satellite cells in long-term denervated muscle to divide. 


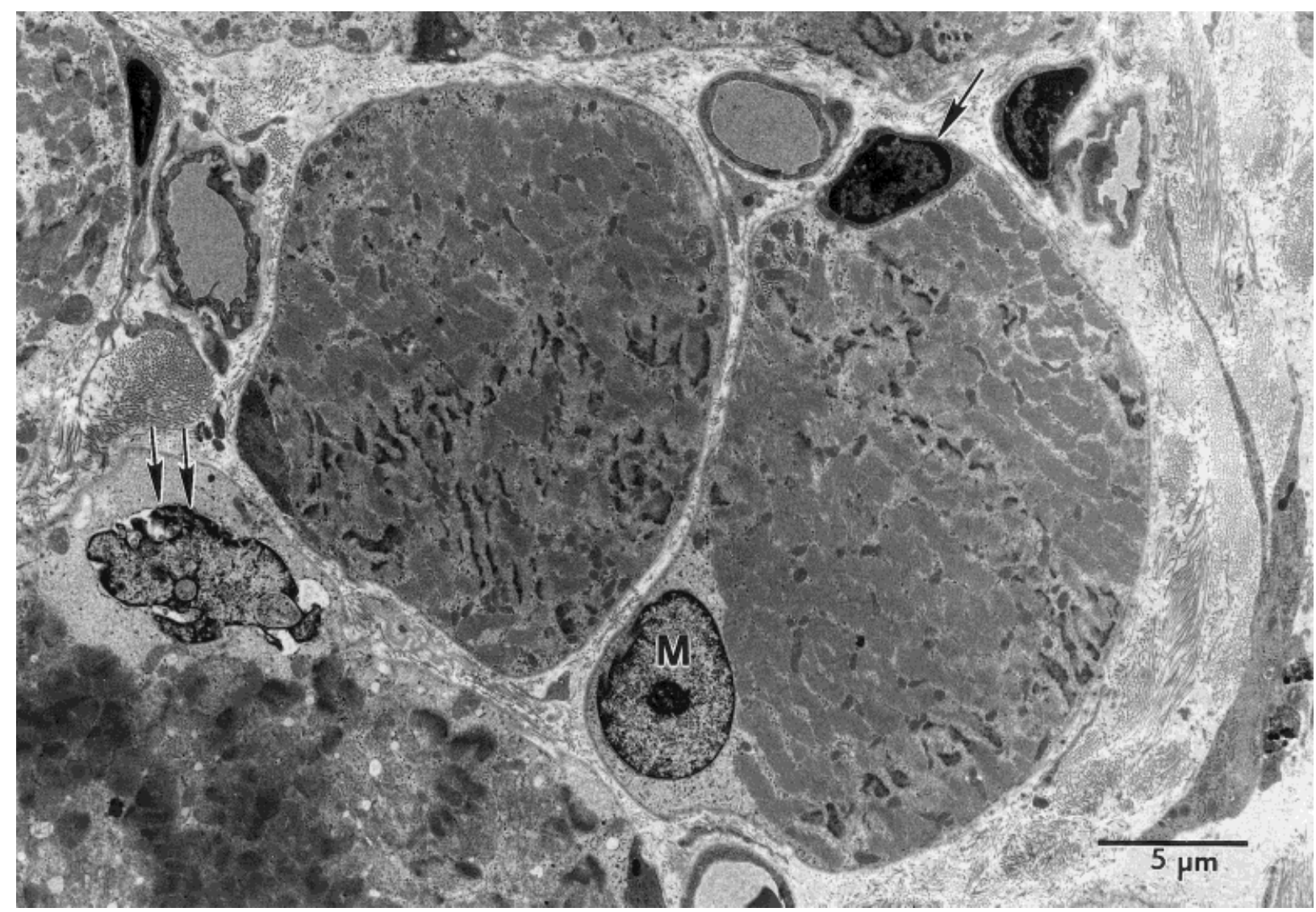

Fig. 5. Electron micrograph of a 2 month denervated rat EDL muscle, showing a satellite cell (arrow) in a normal close relationship to a muscle fiber. The myonucleus (M) of that muscle fiber is surrounded by a region of non-filament containing cytoplasm. In an adjacent muscle fiber a myonucleus (double arrow), similarly surrounded by filament-free cytoplasm, is undergoing early degenerative changes.
With almost no data available on the biology of satellite cells in denervated muscle, it is difficult to determine the cause of the marked decline in their numbers after denervation. Many options exist. One possibility is that certain satellite cells die without being replaced in long-term denervated muscle. Myonuclear death after denervation has been documented through counts (this study) and through morphological observations (Borisov et al., 1995), but the extent to which satellite cells may die is less certain. Another possibility is that satellite cells become incorporated into atrophying or newly forming muscle fibers at a greater rate than they are formed. The paucity of information on satell ite cell proliferation and incorporation into denervated muscle fibers does not allow this possibility to be assessed. There is morphological evidence for the formation of new muscle fibers in longterm denervated muscle (Carraro et al., 1985; Schmalbruch and Lewis, 1994), and experimentally several investigators have shown that long-term denervated muscle can regenerate (Gulati, 1988; Kaminska and Fidzianska, 1990). It has been suggested (I rintchev et al., 1990) that exhaustion of the satellite cell pool could be one of the reasons for poor restoration in long-term denervated muscle. Further information on the behavior of individual satellite cells in denervated muscle must be obtained before the data reported here can be integrated into an overall understanding of cellular aspects of atrophy in long-term denervated muscles.

The reduction in mean number of myonuclei per muscle fiber proceeded in an apparently linear fashion for the first 7 months after denervation, with a net loss of approximately one myonucleus/muscle fiber/day. Results of the present study clearly show that after denervation myonuclear loss is preceded by a significant loss of cytoplasmic volume. Whether myonuclear loss is caused by or merely associated with cytoplasmic loss cannot be determined from the present study, but certainly during the period of study reported here there is no trend toward restoring the control-level nucleocytoplasmic ratio despite the loss of myonuclei. This suggests that after denervation theintracellular dynamics controlling nuclear territories (Landing et al., 1974; Hall and Ralston, 1989) differ from those in normal muscle. Myonuclear death is certainly a significant component contributing to the total loss of myonuclei (Borisov and Carlson, 1995), but the overall dynamics leading to the net loss of one myonucleus per day are not understood. Of particular importance is the bal ance between the potential addition of satellite cell progeny to the atrophying muscle fibers and myonuclear loss dueto cell death. A question that cannot be answered by 


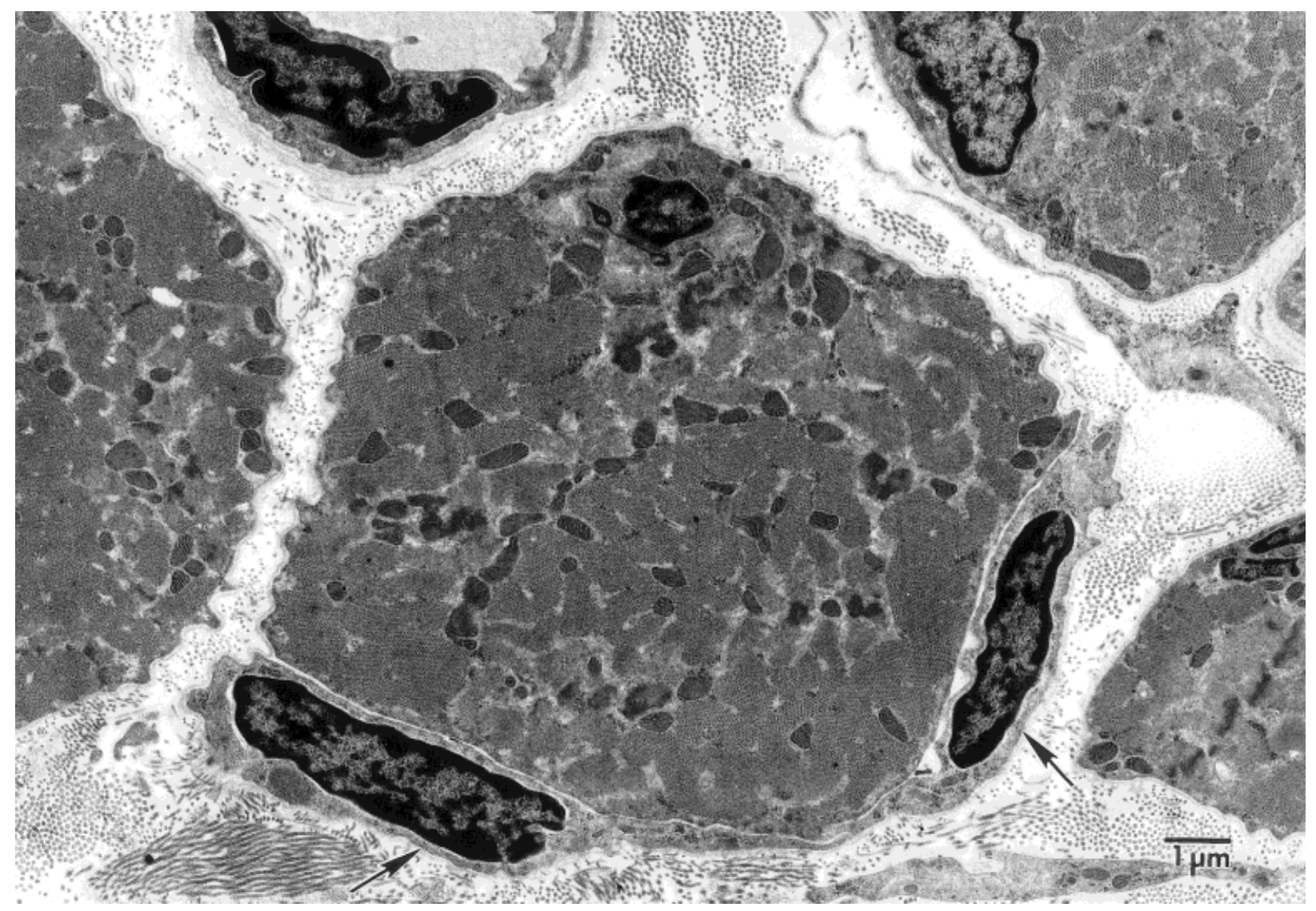

Fig. 6. Electron micrograph of a 4 month denervated rat EDL muscle showing two satellitecells (arrows) beneath the basal lamina of a single muscle fiber. Long cytoplasmic processes extend from each satellite cell, and one satellite cell is partially pulling away from the muscle fiber.

the present set of data is whether myonuclear loss follows a steady pattern of attrition or if bursts of myonuclear death alternate with periods of quiescence. Another finding in this study that cannot be readily explained by the descriptive data is the clumping of myonuclei in 7 month denervated muscle fibers (Fig. 2). Is this due to migration and aggregation of myonuclei, or is it the result of massive death of myonuclei and the proliferation of satellite cells and the local incorporation of their progeny into the atrophic muscle fiber?

In summary, the analyses reported here show that, foll owing denervation, the rat EDL muscle undergoes a rapid course of atrophy, with an early loss of muscle cytoplasm followed by a steady loss of myonuclei. The satellite cell population increases dramatically during the first 2 months of denervation, but subsequently this is followed by a pronounced loss. These morphological findings correlate closely with the ability of the denervated EDL muscleto become restored after transplantation (Carlson et al., 1996), but whether or not the numerical data reported here are sufficient to explain the reduced restorative capacity of long-term denervated muscle remains to be determined.

\section{ACKNOWLEDGMENTS}

This study was supported by grant PO1 AG-10821 from the NIH. Thanks are due to Thomas Komorowski for technical assistance and Sandra Stewart for secretarial support.

\section{LITERATURE CITED}

Aloisi, M., I. Mussini, and S. Schiaffino (1973) Activation of muscle nuclei in denervation and hypertrophy. In: Basic Research in Myology. B.A. Kakulas, ed. Excerpta Medica, Amsterdam, pp. 338-342.

Blaivas, M., and B.M. Carlson (1991) Muscle fiber branchingdifference between grafts in old and young rats. Mech. Ageing Dev., 60:43-53.

Borisov, A.B., and B.M. Carlson (1995) Loss of nuclei in denervated muscle. Possible cellular mechanisms. FASEB J ., 9:A825 (abstract).

Cardasis, C.A., and G.W. Cooper (1975) An analysis of nuclear numbers in individual muscle fibers during differentiation and growth: A satellite cell-muscle fiber growth unit. J. Exp. Zool., 191:347-358.

Carlson, B.M., L. Billington, and J .A. Faulkner (1996) Studies on the regenerative recovery of long-term denervated muscle in rats. Restor. Neurol. Neurosci., 10:77-84.

Carlson, B.M., and J .A. Faulkner (1988) Reinnervation of long-term denervated rat muscle freely grafted into an innervated limb. Exp. Neurol., 102:50-56.

Carraro, U., D. Morale, I. Mussini, S. Lucke, M. Cantini, R. Betto, C. Catani, L.D. Libera, D.D. Betto, and D. Noventa (1985) Chronic denervation of rat hemidiaphragm: Maintenance of fiber heterogeneity with associated increasing uniformity of myosin isoforms. J . Cell Biol., 100:161-174

Gibson, M.C., and E. Schultz (1983) Age-related differences in absolute numbers of skeletal muscle satellite cells. Muscle Nerve 6:574-580. 
Gulati, A.K. (1988) Long-term retention of regenerative capability after denervation of skeletal muscle, and dependency of late differentiation on innervation. Anat. Rec., 220:429-434.

Gulati, A.K. (1990) Restoration of denervated skeletal muscle transplants after reinnervation in rats. Restor. Neurol. Neurosci., 2:23-29.

Gutmann, E., ed. (1962) The Denervated Muscle. Praha, Publishing House of Czechosl ovak Academy of Science.

Hall, Z.W., and E. Ralston (1989) Nuclear domains in muscle cells. Cell, 59:771-772.

Hanzliková, V., E.V. Macková, and P. Hník (1975) Satellite cells of the rat soleus muscle in the process of compensatory hypertrophy combined with denervation. Cell Tissue Res., 160:411-421.

Harrison, D. (1989) Current trends in the treatment of established unilateral facial palsy. In: Functional Surgery of the Head and Neck. E. Karcher, ed. Graz, Austria, pp. 9-16.

Hess, A., and S. Rosner (1970) The satellite cell bud and myoblast in denervated mammalian muscle fibers. Am. J . Anat., 129:21-40.

I rintchev, A., A. Draguhn, and A. Wernig (1990) Reinnervation and recovery of mouse soleus muscle after long-term denervation. Neuroscience, 39:231-243.

Kaminska, A., and A. Fidzianska (1990) Regenerative capacity of denervated rat skeletal muscle: Ultrastructural study. Neuropathol. Pol., 28:151-159.

Landing, B.H., L.G. Dixon, and T.R. Wells (1974) Studies on isolated juman skeletal muscle fibers, including a proposed pattern of nuclear distribution and a concept of nuclear territories. Hum. Pathol, 5:441-461.

Lee, J.C. (1965) Electron microscope observations on myogenic free cells of denervated skeletal muscle. Exp. Neurol., 12:123-135.

Lu, D.-X., S.-K. Huang, and B.M. Carlson (1997). An electron microscopic study of long-term denervated rat skeletal muscle. Anat. Rec., 248:355-365.

Mauro, A. (1961) Satellite cell of skeletal muscle fibers. J . Biophys. Biochem. Cytol ., 9:493-495.

Maxwell, L.F., Faulkner, J .A., and G.J . Hyatt. (1974) Estimation of the number of fibers in guinea pig skeletal muscle. J. Appl. Physiol., 37:259-264.

McGeachie, J ., and D. Allbrook (1978) Cell proliferation in skeletal muscle following denervation or tenotomy. Cell Tissue Res., 193:259-267.
Miledi, R., and C.R. Slater (1969) Electron-microscopic structure of denervated skeletal muscle. Proc. R. Soc. Lond. [Biol.], 174:253269.

Moss, F.P., and C.P. Leblond (1971) Satellite cells as the source of nuclei in muscle fibers of growing rats. Anat. Rec., 170:421-436.

Murray, M.A., and N. Robbins (1982) Cell proliferation in denervated muscle: I dentity and origin of dividing cells. Neuroscience, 7:18231833.

Ontell, M. (1974) Muscle satellite cells: A validated technique for light microscopic identification and a quantitative study of changes in their population following denervation. Anat. Rec., 178:211-228.

Ontell, M. (1975) Evidence for myoblastic potential of satellite cells in denervated muscle. Cell Tissue Res., 160:345-353.

Rodrigues, A. de C., and H. Schmalbruch (1995) Satellite cells and myonuclei in long-term denervated rat muscles. Anat. Rec., 243:430-437.

Rosenblatt, J .D., K. Bockhold, D.J . Parry, and T.A. Partridge (1995) Use of single skeletal muscle fibre explants for investigation of muscle cell biology. In: Proceedings of 4th International Muscle Symposium. M. Frey and P. Giovanoli, eds. Universitätspital, Zürich, pp. 9-12.

Schiaffino, S., P. Bormiolo, and M. Aloisi (1976) The fate of newly formed satellite cells during compensatory muscle hypertrophy. Virchows Arch. Abt. B., 21:113-118.

Schmalbruch, H., W.S. Al-Amood, and D.M. Lewis (1991) Morphology of long-term denervated rat soleus muscle and the effect of chronic electrical stimulation. J . Physiol., 441:233-241.

Schmalbruch, H., and D.M. L ewis (1994) A comparison of the morphology of denervated with aneurally regenerated soleus muscle of rat. J . Muscle Res. Cell Motil., 15:256-266.

Snow, M.H. (1977) Myogenic cell formation in regenerating rat skel etal muscle injured by mincing. II . An autoradiographic study. Anat. Rec., 188:201-218.

Snow, M.H. (1983) A quantitative ultrastructural analysis of satellite cells in denervated fast and slow muscles of the mouse. Anat. Rec., 207:593-604.

Sunderland, S. (1978) Nerve and Nerve Injuries, 2nd ed. ChurchillLivingston, Edinburgh.

Sunderland, S., and L.J . Ray (1950) Denervation changes in mammalian striated muscle. J . N eurol. Neurosurg. Psychiat., 13:159-177. 